\title{
ÉLITES EN EL SALVADOR: CAMBIOS Y CONTINUIDADES (2000-2016)
}

\author{
ELITES IN EL SALVADOR: \\ CHANGES AND CONTINUITIES IN THE LAST DECADE (2000-2016)
}

Francisco Robles Rivera

Recibido: 08/02/2017 Aceptado: 02/05/2017

\begin{abstract}
Resumen
En este artículo se analizan los cambios y continuidades en las élites económicas y en los ejes de acumulación en El Salvador en la década del 2000. Se discute que a diferencia de lo que se previó a inicios de los años noventa, es decir, el posicionar a El Salvador como un centro financiero regional, la mayor apertura comercial y la venta de empresas de capital privado salvadoreño ha modificado los ejes de acumulación de estas, orientando sus intereses, en especial, a las economías vinculadas con las remesas y los servicios. Finalmente, se discute de forma breve el impacto que tuvieron los gobiernos del FMLN y sobre todo la emergencia de nuevos agentes económicos vinculados al proyecto de ALBA petróleos.
\end{abstract}

Palabras clave: Élites; El Salvador; remesas; economía; poder; acumulación.

\begin{abstract}
This article analyzes the changes and continuities in the economic elites in El Salvador in the last decade, as well as their main changes in the axes of accumulation. It is argued that unlike what was foreseen at the beginning of the 1990s, the trade liberalization and the sale of Salvadoran private companies have modified the axes of accumulation. In this regard, economic elites have focused their interests mainly to the economies related with remittances and services. Finally, the impact of the leftits governments (FMLN) and the emergence of new economic agents linked to the ALBA petroleos project is briefly discussed.
\end{abstract}

Keywords: Elites; El Salvador; remittances; economy; power; accumulation. 


\section{Introducción}

En las últimas cuatro décadas, Centroamérica ha experimentado cambios radicales en su estructura económica y en los diferentes actores que emanan de estas transformaciones. Estos cambios han ocurrido en distintos momentos y niveles para cada país de la región. Comparativamente al resto de Centroamérica, en El Salvador los cambios tuvieron lugar de manera rápida y amplia, sobre todo en materia de privatizaciones y liberalización comercial (Robinson, 2003; Segovia, 2005).

Durante los años noventa una renovada élite (económica y política) logró recrear en El Salvador un Estado y un modelo de acumulación funcional a sus nuevos intereses particulares (A. Schneider, 2012). La privatización, refundación y posterior expansión regional de los capitales financieros en esa década favoreció, a su vez, la diversificación sectorial de las élites, así como el acceso a otros mercados de la zona. Asimismo, la liberalización comercial permitió ampliar las bases de las élites vinculadas con el sector importador y el sector comercial, quienes, junto con la industria de maquila se convirtieron durante los años noventa en los principales focos de acumulación salvadoreña (Robinson, 2003).

En el marco general de consolidación de estas élites, la estrategia de acumulación que se favoreció para integrar la economía salvadoreña a los mercados globales fue en función de una mayor penetración del capital regional y transnacional en sectores estratégicos de la acumulación nacional, sobre todo en los sectores de electricidad, seguros, pensiones y telecomunicaciones (Robles-Rivera, 2010; Segovia, 2002).

Sin embargo, no todo ha permanecido como se proyectaba a inicios de la década de los 2000 por parte de las élites salvadoreñas, es decir, haber convertido en el corto plazo a El Salvador en un centro financiero regional (Segovia, 2002). Actualmente, por el contrario, la estrategia ha cambiado, las élites se enfrentan a un shock competitivo nacional y regional sin precedentes, lo cual, las ha obligado a adaptarse y a (re) establecer nuevos vínculos intra y extra familiares para sobrevivir (Bull, Castellacci y Kasahara, 2014). Los conglomerados financieros base de la nueva expansión regional en manos de las élites salvadoreñas se vendieron a otros regionales y transnacionales (Kasahara, 2012). Los impactos positivos que se esperaron de la dolarización se agotaron rápidamente y por el contrario ha agudizado parte de los problemas estructurales de la economía salvadoreña (Arias-Peñate, 2008). Por último, fracasaron las apuestas para convertir a El Salvador en un centro financiero regional y, recientemente, en un centro regional de distribución y logística.

A lo anterior, corresponde sumar los dos gobiernos consecutivos del Frente Farabundo Martí para la Liberación Nacional (FMLN, 2009-2018) que limitaron la histórica captura del Estado por parte de las élites económicas (Cárdenas y Robles-Rivera, 2017), el rompimiento del poder político-empresarial en dos partidos, el histórico Alianza Republicana Nacionalista (ARENA) y el partido del expresidente 
arenero, Antonio Saca, Gran Alianza por la Unidad Nacional (GANA), así como el surgimiento de una nueva élite económica vinculada al FMLN, todo en un contexto de (pos)crisis económica en los EE. UU., centro del patrón de acumulación salvadoreño.

En la actualidad, las élites salvadoreñas distan mucho de ser aquellas 14 familias oligárquicas, terratenientes, altamente cohesionadas, cafetaleras y agroexportadoras con gran poder político y control sobre las fuerzas armadas del siglo XIX y $\mathrm{XX}$ y son, por el contrario, grupos diversificados bajo el control de una o más familias con intereses mucho más diversificados y en algunos casos con intereses regionales (Bull et al., 2014).

En este trabajo se caracterizarán las élites ${ }^{1}$ a partir de su sólida constitución como un núcleo duro familiar, es decir, su organización; la expansión y la regionalización de sus actividades, no solo producto de la guerra, sino también como resultado de una funcionalización de redes familiares con otras élites en la región (Bull, 2014); la ampliación de sus inversiones a partir de la banca, la disminución del peso económico y político de su base agrícola y su transformación mayoritariamente en élites dependientes de las economías de servicios, así como con una visión más pragmática de formación de nuevas empresas para su posterior venta a capitales regionales o transnacionales.

Además, se discutirán los cambios en los mapas de poder económico de El Salvador que han implicado una ampliada liberalización comercial y de capitales, la privatización de activos públicos altamente rentables, así como la venta de empresas emblemáticas del capital salvadoreño al capital regional y transnacional.

Asimismo, se intenta hacer un esfuerzo de síntesis de los principales cambios en torno al patrón de acumulación en El Salvador, es decir, los cambios en el financiamiento de las élites y la maquila, a uno donde los ejes más rentables del patrón se dejaron en manos de capitales regionales o transnacionales (Bull et al., 2014), el cual puede caracterizarse también por ser altamente dependiente de las remesas y de las economías de servicios.

Por último, el artículo presenta una breve discusión sobre la llegada al gobierno del FMLN y su apoyo a una élite emergente producto de los programas de la Alianza Bolivariana para los Pueblos de Nuestros Pueblos de Nuestra América (ALBA).

\section{Élites en El Salvador: ¿Quiénes y cómo son?}

En la actualidad, la dinámica capitalista de El Salvador, caracterizada por su énfasis en una economía de servicios, altamente dependiente de las remesas y que ha estado penetrada profundamente por el capital regional y transnacional, hace que las concepciones sobre las 14 familias se diluyan en un mar de competencia sin precedentes (Bull, 2013). En este sentido, se entiende a las élites como aquellos individuos cuyo 
capital económico los ubica en una posición de privilegio en la sociedad salvadoreña, el cual, a su vez, se traduce en otros recursos políticos, sociales e ideológicos (Bull, 2014; Durand, 2003; Scott, 2008).

Hasta ahora las principales caracterizaciones provienen de dos enfoques distintos. Por un lado, de la perspectiva de identificar a las élites como grupos de poder, cuyo peso económico se traduce en un poder político (Segovia, 2005); y, por otro lado, se les considera grupos de negocios diversificados propios del capitalismo latinoamericano, definidos por su estructura familiar jerárquica (Bull et al., 2014).

Así las cosas, ¿qué puede decirse sobre su organización, sus grados de expansión o regionalización y sus relaciones con el capital regional y transnacional (subordinación/desnacionalización y sobrevivencia)?

\section{Su organización}

Ben Ross Schneider (2009) ha caracterizado al capitalismo latinoamericano a partir de lo que él llama "las economías jerárquicas de mercado". Esta variedad se caracteriza por grupos de empresas diversificadas, activas simultáneamente en 4 o 5 sectores, y en las cuales existe un control jerárquico familiar a través de participaciones significativas u otras conexiones financieras. Estas compañías, a su vez, pueden ser identificadas y caracterizadas a partir de tres categorías. Los "grupos orgánicos", diversificados a partir de las lógicas de las economías de gama (scope) y de integración vertical, con un manejo centralizado y fuertes sinergias en la organización, personal y experiencia. Los portafolios, cuyo origen está en el manejo de riesgos, con una amplia gama de diversificación, más orientado a la compra de empresas que a su creación. Y los grupos inducidos políticamente, los cuales nacen a partir de incentivos o directrices gubernamentales (B. R. Schneider, 2009).

Para el caso salvadoreño, los cambios ocurridos en las décadas recientes y la orientación histórica y propia de las élites han permitido delimitar ciertas particularidades, atinentes a las categorías de Schneider. La literatura al respecto señala que una de sus características principales está determinada por las raíces históricas (Albiac, 1998; Paniagua-Serrano, 2002); es decir, aquellas élites cuya herencia se puede trazar a las oligarquías tradicionales del siglo XIX (Dueñas y Baldocchi por ejemplo), que se modernizaron en la década de los setenta y ochenta, y aquellas otras de más reciente data, cuyos orígenes históricos se encuentran en la migración, sobre todo de árabes palestinos a El Salvador (como es el caso de las familias Simán² o Zablah³) ${ }^{4}$ (Albiac, 1998).

Además de su origen, una característica singular de las élites salvadoreñas, hasta el día de hoy, es su sólida constitución a partir de redes familiares cerradas (Paniagua-Serrano, 2002). Esto les ha permitido crear redes familiares nacionales, regionales y extrarregionales capaces de acaparar y expandir mercados y sectores, así como servir de escudo de protección a sus intereses en tiempos de acelerada competencia 
(Bull, 2013). Además de esto, ha permitido ampliar las operaciones de sus empresas a partir de una empresa "buque bandera", que asume el rol de expandir y crear nuevos mercados nacional o regionalmente, como es el caso de los centros comerciales de la familia Poma.

A diferencia de los años noventa, cuando la diversificación y operación de las empresas se determinaba desde el sector financiero como un trampolín de inversiones; con la venta de los bancos a mediados de los años 2000 y la ampliación de la competencia con capitales regionales y transnacionales, ahora la orientación se ha centrado en sectores en donde poseen ventajas, experiencia, redes y no requieren grandes cantidades de dinero en inversiones.

La organización de las élites empresariales salvadoreñas, de acuerdo con (Bull et al., 2014) se podría caracterizar por una combinación de grupos orgánicos (Poma, Quirós, Agrisal, Simán y Salumé), es decir, élites empresariales en varias actividades económicas, pero con una estructura familiar jerárquica bastante clara, y élites empresariales cuyos horizontes de inversión están basados en oportunidades de corto plazo (Cristiani y Kriete) y, por tanto, más cercanas a la definición de élites de portafolio. Como se verá más adelante, el primer gobierno del FMLN también facilitó la emergencia temporal de otras élites empresariales, que políticamente podrían llamarse "inducidas" (ALBA petróleos).

\section{Expansión y regionalización}

¿Qué hace de la región un mercado tan atractivo para las élites empresariales centroamericanas? En su estudio, Alexander Segovia (2005) caracterizaba entre otros aspectos la cercanía, las similitudes económicas y sociales y los aprendizajes de la operación corporativa para expandirse a otros mercados. Recientemente, el propio modelo de desarrollo implementado en la región ha posibilitado no solo la apertura de ejes de acumulación regionales (turismo, por ejemplo), sino también esquemas legales y económicos a través de acuerdos comerciales y políticos favorables a sus intereses (tratados de libre comercio y el Proyecto Mesoamérica).

Además, las propias redes interfamiliares creadas entre las élites empresariales de los distintos países para operar en los diferentes mercados y el financiamiento de campañas políticas en las naciones de la región han posibilitado una expansión regional, pero sobre todo la "integración real" de las élites en una carretera de inversiones de México a Colombia (Robles-Rivera, 2011; Segovia, 2005).

En el caso de El Salvador, la guerra, la caída en los precios de los productos tradicionales de exportación y, con esto, el colapso del sector agrícola tradicional a finales de la década de los setenta provocó el exilio de muchos de los grandes capitales y su establecimiento en mercados regionales, particularmente en Miami, EE. UU. ${ }^{5}$ Con la llegada de Alfredo Cristiani al poder (1989) y la implementación del nuevo modelo 
económico, la privatización de la banca y la ampliación de recursos provenientes de las remesas se les permitió a las élites salvadoreñas realizar una expansión sin precedentes, sobre todo en materia financiera, como es el caso del Banco Cuscatlán ${ }^{6}$ y del Banco Uno, ${ }^{7}$ así como a partir de centros comerciales, por ejemplo Multiplaza. ${ }^{8}$

Pensar en la regionalización de las élites en El Salvador implica, al menos, considerar que las redes de contactos creadas durante la guerra y la ausencia física de las élites en el país allanaron el terreno y las condiciones para su regionalización; esto como parte de la dinámica de crecimiento de las élites empresariales y como una puerta para enfrentar la transnacionalización de las economías regionales (Bull, 2013; Segovia, 2005).

Ahora bien, Segovia (2005) analiza nueve grupos de poder económico, mientras que Bull (2013) solo contabiliza cuatro élites empresariales regionalizadas, pues su grado de regionalización depende de un manejo integrado y una visión regional, mientras que para Segovia depende de la instalación o no de una empresa fuera de sus fronteras nacionales.

De acuerdo con Bull (2013), la familia Poma es la que se ha expandido de forma más fuerte desde México hasta Colombia. Sus inversiones se cuentan en venta de vehículos (Excel Automotriz), centros corporativos (Plaza Roble y Bogotá Corporate Center), centros comerciales (Multiplazas) y franquicias hoteleras (Marriott International, InterContinental Hotels Group y Choise Hotels International). Por su parte, la familia Simán se ha expandido en sectores más específicos sobre todo en tiendas por departamentos (Simán, La Perfumerie, Prisma Moda, Grupo Unicomer y Zara), industria alimentaria y algunas franquicias como Radio Shack y Lucky Dollar. La familia Quirós menos diversificada, pero con una posición importante en venta de vehículos (Grupo Q), exportación de café (Quality Grains), hotelero vía franquicias (Holliday Inn y Crowne Plaza), venta de vehículos (Star Motors y Rensica) y, por último, el desarrollo inmobiliario con la empresa Agrisal, la cual se ha focalizado en esta actividad luego de la venta de la histórica cervecería La Constancia a SabMiller.

En otra categoría, Bull (2013) coloca a los grupos empresariales que han utilizado su expansión regional para su futura venta a Corporaciones Multinacionales o una expansión regional localizada. En el caso la familia De Sola su expansión se ha dado sobre todo en turismo y desarrollo inmobiliario, mientras que en el caso de la familia Cristiani ha sido sobre todo a través de servicios en informática y agricultura. La familia Bellismelis, herederos de la venta del Banco de Comercio, se han expandido principalmente al mercado de los servicios de logística y almacenes. Por su parte, la familia Kriete, tal vez de las élites empresariales más fuertes, mantiene una estrecha alianza con el capital colombiano (Familia Efromovich) en transporte aéreo (TACA). Mientras que la familia Salume se mueve en cadenas de restaurantes, alimentos y bebidas, y desarrollo inmobiliario (La Joya). Por último, la élite alrededor de ADOC, la familia Palomo Meza, ha abierto 220 tiendas en toda la región y 
posee tres fábricas de zapatos; su expansión regional ha priorizado exclusivamente el sector del calzado (Tabla 2).

Ante esto, la formas en que está diseñado el patrón de acumulación salvadoreño, si bien garantiza espacios de acumulación para dichas élites a nivel local, también la lógica propia regional del modelo y la forma de pensar(se) de estas les ha facilitado una expansión que ha implicado mayores inversiones y tasas de ganancia.

\section{Desnacionalización vrs. Sobrevivencia}

Como se ha destacado, la liberalización indiscriminada y la privatización han modificado por completo el mapa de poder económico salvadoreño. Como se puede caracterizar también para otros países de la región, el capitalismo centroamericano y sus bases nacionales han sufrido, al menos, dos cambios importantes (Robles Rivera, 2014). Por un lado, la privatización de empresas tradicionalmente estatales a favor de las élites nacionales o transnacionales durante los años noventa y un proceso más reciente vinculado a la venta de empresas bandera de las élites centroamericanas a capitales regionales, colombianos y mexicanos, principalmente. Por otro lado, las ventas más importantes se dieron en el sector bancario, donde las entidades financieras fueron revendidos a capitales de los EE. UU., Canadá y Colombia. Ante esto, ¿qué implicaciones han tenido estas ventas al mapa de poder y las élites empresariales?

Por un lado, se mantiene la tesis de Segovia (2005) de una amplia extranjerización de la economía determinada, sobre todo, por la presencia de grandes oligopolios regionales y transnacionales en sectores clave de la acumulación nacional (banca, telecomunicaciones, electricidad y seguros). Por otro lado, el desplazamiento de las élites a sectores de servicios, comercio, turismo, consumo y construcción. Sin embargo, a diferencia de lo señalado por Robinson (2003) -“globalizarse o perecer"-, en general las élites salvadoreñas han sabido adaptarse e incluso oponerse a acuerdos que puedan afectar sus intereses. Este ha sido el caso de la oposición de la familia Kriete a la alianza entre AVIANCA y United Airlines, pues, según los salvadoreños afectaría sus inversiones e intereses.

Lo anterior permite precisarlas conceptualmente y diferenciarlas como élites nacionales y regionales según su desarrollo y grado de expansión, pues si bien hay una excesiva adjetivación de las élites centroamericanas como élites transnacionales, las lógicas propias del capitalismo regional, el tamaño de las economías y el de las propias élites determinan aún grados de subordinación al capital transnacional.

Sin embargo, para Bull (2013) no toda relación con el capital transnacional implica subordinación, sino más bien grados de esta (franquicias, joint-ventures, alianzas estratégicas). Para la autora, las élites son fundamentales a la hora de invertir en la región por su conocimiento (know how) y por sus grados de consolidación en redes, lo que facilita la expansión del capital transnacional. Además, las ventas recientes que 
han hecho las élites de algunas de sus empresas familiares, les ha permitido aumentar su poder económico y re-invertir en nuevos emprendimientos (Anexo 1).

Hoy las élites salvadoreñas conservan como característica central su construcción en torno a núcleos familiares consolidados, con diversos grados de expansión regional que dependen del mercado donde operan, su vínculo y niveles de competencia con otras élites regionales y transnacionales; las lógicas del patrón de acumulación nacional o regional y su visión y organización empresarial. Si bien la desenfrenada liberalización comercial y los tratados de libre comercio han posibilitado una carretera de inversiones desde México hasta Colombia, también ha acrecentado la competencia con capitales regionales y transnacionales, todo en orden con una reestructuración nacional, regional y global de las cadenas de producción, competencia y concentración (Salas-Porras, 1992).

\section{Rupturas y continuidades en los ejes de acumulación de El Salvador}

La dependencia histórica centroamericana de los bienes tradicionales de exportación, como base del modelo de desarrollo y del patrón tradicional de acumulación, se vio quebrantado por las nuevas dinámicas políticas y económicas impulsadas e impuestas en la región a través de los programas de ajuste estructural (Segovia, 2004).

Para Segovia (2004), este "quiebre estructural" significa el desplazamiento de las exportaciones tradicionales por las no tradicionales y nuevas fuentes de divisas para los Estados centroamericanos. Además de esto, representa la ampliación, la apertura y la reubicación de los beneficios en nuevos espacios de acumulación, más allá de la tradicional tenencia de la tierra. En este sentido, la liberalización del comercio y de capitales, la privatización y "modernización del Estado", así como las consecuentes políticas en materia cambiaria y fiscal, tuvieron como objetivo central ampliar los beneficios a élites específicas.

En el caso de El Salvador, la herencia de una nueva élite económica tuvo sus raíces en la nacionalización de la banca de 1980. De acuerdo con Kasahara (2012), este movimiento logró romper con los lazos entre el poderoso sector agrícola y el financiero, lo cual provocó que las familias vinculadas tradicionalmente a la banca perdieran parte del poder económico adquirido previamente; esto facilitó que aquellas élites vinculadas a otros sectores económicos (café y servicios) y menos afectadas, asumieran el control de las asociaciones empresariales y del recién formado partido Alianza Republicana Nacionalista (ARENA).

En los años noventa, y de la mano de una coyuntura global de amplia especulación y financiarización de las economías, la apuesta del binomio gobierno-élites se centró en la captura del sector bancario salvadoreño. Así, con el auspicio del gobierno de Alfredo Cristiani, prominente miembro de la élite tradicional modernizada, se aprobó la Ley de Privatización de los Bancos Comerciales y de las Asociaciones de Ahorro 
y Préstamo. Para esta venta, el Estado salvadoreño saneó/recapitalizó las carteras de varias asociaciones de ahorro y préstamo y de los cinco bancos comerciales nacionalizados en la década de los ochenta. La venta si bien buscó la "no" concentración de capital, al prohibir el control de más de un 5 por ciento de las acciones, los fenómenos del "testaferrismo" consolidaron la emergencia de una nueva élite financiera salvadoreña (Segovia, 2002) (Tabla 1).

En el contexto de las negociaciones de paz, las élites asumieron un papel protagónico, pues tenían como horizonte la reactivación de la economía y su inserción en los mercados globales (Rettberg, 2007). Esta política les permitió, entonces, retomar el sector financiero y ampliar su diversificación; esto último fue producto, por un lado, de una extensa gama de recursos financieros frescos alimentados por las remesas y de dineros para el posconflicto, y, por otro lado, consecuencia de la adquisición de empresas tradicionalmente estatales. Junto a lo anterior, los límites impuestos a la compra de acciones convirtieron al sector financiero privado salvadoreño en poco apetecible para los grandes capitales transnacionales (Kasahara, 2012).

Tabla 1

EL CONTROL DE LOS BANCOS EN EL SALVADOR ANTES Y DESPUÉS DEL AJUSTE ESTRUCTURAL

\begin{tabular}{lll}
\hline Bancos & $\begin{array}{l}\text { Dueño } \\
\text { antes de 1980 }\end{array}$ & $\begin{array}{l}\text { Dueño } \\
\text { después de 1990 }\end{array}$ \\
\hline Salvadoreño & Guirola & Simán \\
Agrícola & Escalante-Sol Millet & Baldochi \\
Cuscatlán & Roberto Hill & Samayoa-Cristiani \\
Comercio & Regalado Dueñas & Bellismelis García Prieto \\
Desarrollo & & Salaverria \\
Bancor & & Roberto Hill \\
Bancasa & & Zablah \\
Credisa & & Dutiriz \\
Credomatic & & Murray Meza-Pellas \\
Ahorromet & & Poma \\
\hline
\end{tabular}

Fuente: Albiac (850).

La protección estatal, la propia lógica del modelo salvadoreño y la llegada masiva de remesas desde el exterior le posibilitó a la élite expandirse a otros mercados nacionales y regionales y su constitución en ocho grandes conglomerados a finales de la década de los noventa y principios del nuevo siglo (Segovia, 2005). 
Asimismo, y de la mano de los recursos financieros, la nueva política de incentivos fiscales, los beneficios de la Iniciativa de la Cuenca del Caribe y los bajos salarios favorecieron el desarrollo de una boyante industria de maquila, en la cual, a diferencia del resto de los países centroamericanos, la mayoría del capital provenía de las élites locales.

En el caso de la primera década del siglo XXI, el patrón de acumulación salvadoreño con un fuerte anclaje en el sector financiero y la maquila se vio modificado radicalmente, al menos, por cuatro condiciones: i) la dolarización, ii) el tratado de libre comercio con los EE. UU., iii) la venta de los bancos privados salvadoreños a conglomerados regionales y transnacionales y iv) la crisis económica internacional.

En primera instancia, en el caso de la dolarización, puesta en marcha a través de la Ley de Integración Monetaria en el año 2000, se pretendió dar por finalizado el proceso promovido durante el ajuste estructural por las élites salvadoreñas para convertir al país en un centro financiero regional después de Panamá, y beneficiar particularmente a los banqueros y a los importadores (Segovia, 2002). La dolarización, sin embargo, implicó la renuncia del Estado a controlar la cantidad de dinero en circulación, y permitió consolidar el proceso de expansión financiera de los EE. UU. en la región, es decir, de una unión monetaria ${ }^{9}$ sin asumir costos y responsabilidades (Acosta, 2001; Guzmán López y Salinas Ventura, 2008; Madrid, 2009). Asimismo, como señala Arias (2008) a diferencia de lo vaticinado por los promotores de la dolarización, la economía salvadoreña no creció en los sectores que más empleos generan (agricultura y medianas y pequeñas empresas), tampoco bajaron los precios de los productos como se había prometido y le impidió al gobierno salvadoreño, en tiempos de crisis económica, tomar medidas para paliar los efectos sobre su economía.

Segundo, con la intención de profundizar en torno a un patrón de acumulación extra regional y con EE. UU. como principal mercado, el TLC firmado en el 2004 tenía como objetivo fortalecer la visión de una América Central como un mercado integrado y atractivo a la inversión extranjera directa (Bull, 2013). Más importante aún, era el objetivo de blindar jurídicamente las inversiones privadas en la región, al ofrecer garantías y nuevos espacios para la participación privada en sectores altamente redituables en el futuro cercano (salud, bioprospección, minería, inversiones, entre otros) (Robles-Rivera, 2011).

Tercero, la venta de los bancos iniciada en el 2005 constituyó la estocada final al proyecto de El Salvador como centro financiero regional. Según señala Kasahara (2012), la dolarización de la economía y la imposibilidad de competir contra el capital transnacional, así como la fragmentada y poco clara estrategia bancaria de las élites, favorecieron su venta. En el caso específico de El Salvador, estas se iniciaron con la venta del Banco del Comercio ${ }^{10}$ a Scotiabank, la del Banco Salvadoreño ${ }^{11}$ en el 2007, la de las financieras Banagrícola ${ }^{12}$ a Bancolombia $y$, finalmente, las fusiones del 
Grupo Uno ${ }^{13}$ y Cuscatlán ${ }^{14}$ para el nacimiento de Citi Centroamérica (Robles Rivera, 2011a; (Kasahara, 2012; Robles-Rivera, 2011).

Con la venta de los principales conglomerados financieros a capitales regionales y transnacionales se dio una reconfiguración del mapa de poder económico de las élites. Primero porque significó la salida definitiva de las élites que se habían alimentado y expandido del sector financiero a otras actividades económicas. Segundo, porque esta salida a otras áreas se dio debido a que el sector financiero les abrió las puertas de inversión a otros mercados, y porque la venta les facilitó una mayor liquidez producto de la venta. En tercer lugar, las redes creadas interempresarialmente con los banqueros salvadoreños fueron desmanteladas y sujetas a las decisiones de terceros países y gerentes luego de su venta; lo cual provocó un duro golpe a los empresarios salvadoreños dependientes del financiamiento y crédito post crisis económica.

Cuarto, la crisis económica en los EE. UU. socavó las bases del propio patrón de acumulación de El Salvador debido a cuatro razones fundamentales. En primer lugar, la centralidad de este en las exportaciones privilegió el mercado estadounidense, las cuales, como era de esperar, se contrajeron de manera importante, principalmente en el sector de la maquila (Figura 1). En segundo lugar, cayó el índice de volumen de actividad económica y aumentó la inflación. En tercer lugar, se re abrió con más fuerza el debate sobre la insostenibilidad de la dolarización y la dependencia de una economía en crisis, cuyas políticas monetarias y cambiarias afectan directamente a El Salvador. En cuarto lugar, y vinculado con la "política" de exportación de gentes, la crisis provocó la contracción de una buena parte de las fuentes de empleo de migrantes salvadoreños en los EE. UU. y con esto la caída en las remesas enviadas por estos a El Salvador (Figura 2).

Así las cosas, quedan por discutir cuáles espacios y ejes de acumulación han dejado de ser prioridad para las élites empresariales salvadoreñas y cuáles han sido los ejes prioritarios de estas.

\section{Ejes de acumulación: los que fueron y los que quedan}

Los cambios en las dinámicas propias del capitalismo salvadoreño han modificado y reorientado los ejes de acumulación para las élites salvadoreñas. Estos cambios han sido producto de guerra; la acelerada competencia con capitales regionales y transnacionales; la privatización de ejes de acumulación nacionales estratégicos; venta de la banca salvadoreña en los años recientes y una mayor vulnerabilidad respecto al mercado internacional, sobre todo en maquila.

En este caso, si bien la maquila es y sigue constituyendo una fuente de acumulación para algunas élites salvadoreñas, la vulnerabilidad del mercado, la crisis económica de 2008, la competencia internacional con China, Vietnam, Paquistán, entre otros países, y la dignificación de algunos derechos laborales y salarios 
principalmente, hacen de este un sector menos "rentable" para las élites. Como se puede ver en la Figura 1, si bien la maquila manifestó un crecimiento importante desde la década del noventa hasta el año 2004, alcanzando los casi dos mil millones de dólares en exportaciones, desde el año 2005 y de la mano de los factores señalados el sector maquilero sigue sin poder recuperarse.

Figura 1

EXPORTACIONES DE MAQUILA EN EL SALVADOR

(1999-2016)

(MILLONES DE DÓLARES)

2500

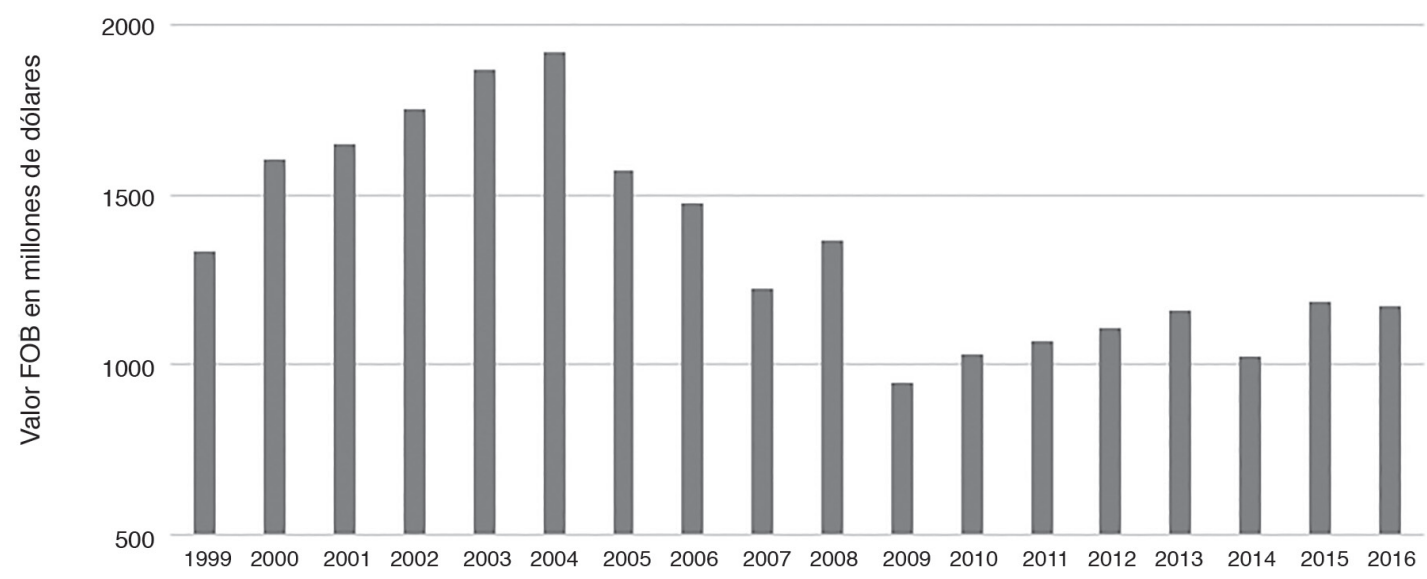

Fuente: Banco Central de Reserva de El Salvador.

Al igual que en la maquila, la venta de la banca volcó el eje de acumulación en finanzas a favor de los grandes capitales regionales y transnacionales, tal y como había sucedido con las telecomunicaciones, o la electricidad, entre otros, lo cual permite afirmar la salida de las élites de los ejes de acumulación más rentables de la economía salvadoreña (Bull, 2013).

A diferencia de lo sucedido con la maquila y las finanzas, el eje de acumulación de la "exportación de gentes e importación de remesas" ha estado creciendo. Las remesas más allá de la discusión social que pueda implicar han favorecido la liquidez de la economía salvadoreña y los ingresos. Estos flujos de dólares se han mantenido crecientes en las últimas décadas pasando de representar 790 millones de dólares en 1991 a 4279 millones en 2015 (Figura 2). 
Figura 2

INGRESO DE REMESAS FAMILIARES EN EL SALVADOR

1991-2015

(MILLONES DE DÓLARES)

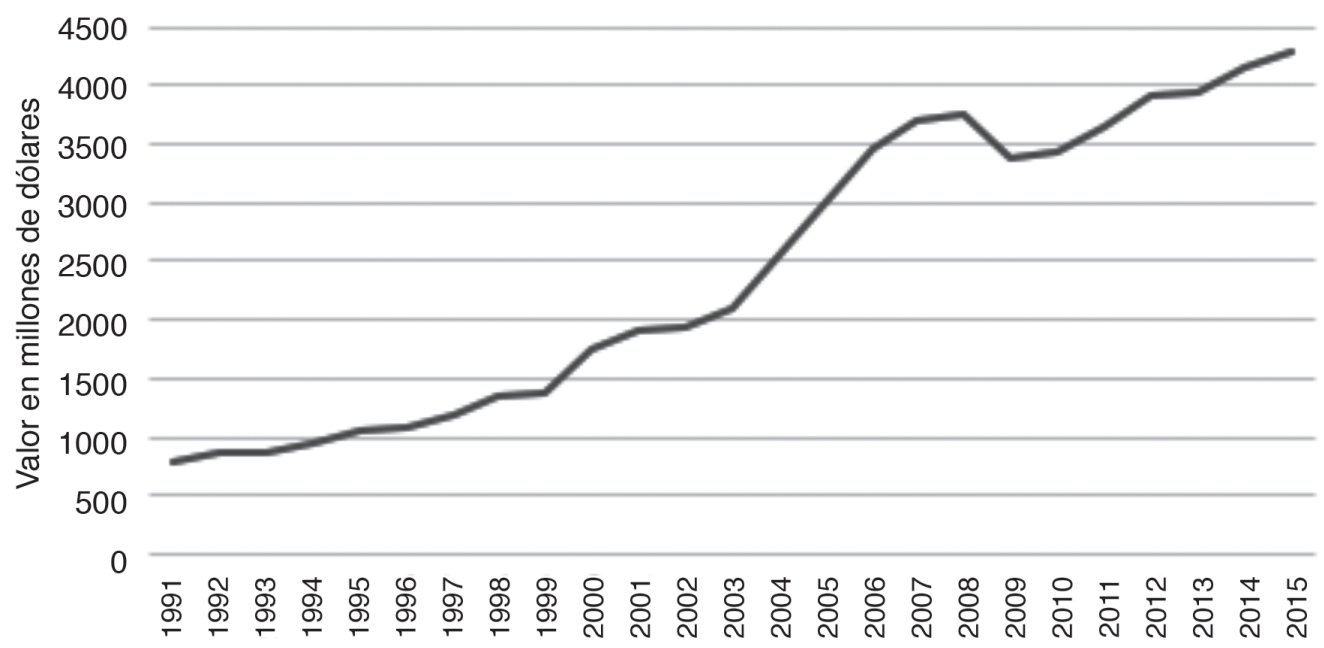

Fuente: Banco Central de Reserva de El Salvador.

Por su parte, la dinámica propia de las remesas ha permitido un aumento del consumo total sin precedentes en El Salvador, representando para el 2007 un 107 por ciento del PIB (Guzmán y Salinas, 2008). En este sentido se puede afirmar, siguiendo a Rocha que, que

Las remesas están haciendo posible la ampliación de los mercados, la urbanización sin respaldo productivo y la graduación masiva no de ciudadanos, sino de consumidores. Las élites y el Estado no han hecho un esfuerzo transformador. Simplemente se han montado sobre las oportunidades que les abren... (Rocha, 2013, párr. 33).

Un ejemplo particular del crecimiento y expansión en torno a los ejes de acumulación abiertos por las remesas lo constituye $\mathrm{TACA}^{15}{ }^{15}$ hoy parte del holding colombiano-salvadoreño AVIANCA:

En 1979 el patrimonio de TACA se reducía a tres aviones para pasajeros, dos aviones cargueros y escasas rutas de viaje limitadas a Centroamérica. Había 300 empleados trabajando para la compañia. Veinte años después TACA había expandido sus rutas hacia Estados Unidos y Sudamérica y tenía 5,600 empleados y una flota de 81 aviones, 33 de ellos con capacidad para 
110 y 150 pasajeros. En el interin había adquirido AVIATECA de Guatemala (1989), LACSA de Costa Rica y LANICA de Nicaragua (1992) (Rocha, 2013, párr. 31).

Este crecimiento de Taca, como señala Rocha, debe su éxito al efecto de flujo migratorio centroamericano hacia los EE. UU. y Canadá. Como se puede ver en la Figura 3, cuando las personas viajan a El Salvador una mayoría de personas (38 \%) lo hace a través de TACA; empresa que creó el programa VFR (Visit Friends and Relatives) con el objetivo de acaparar el mercado de "los que regresan" y "el hermano lejano".

Asimismo, como señala Rocha (2013),junto con las remesas, y la compra de boletos áerreos, los salvadoreños que regresan gastan sumas considerables en diversión con sus familias, típicamente al menos mil dólares por estancia. Las remesas por tanto deben ser consideradas como el eje de acumulación por excelencia del patrón salvadoreño, sobre todo por la diversidad de puertas que ha abierto para la acumulación de capital a través del consumo de bienes, servicios y telecomunicaciones, principalmente.

En este mismo sentido, alrededor de las remesas se han organizado diferentes economías de escala, actores y grupos que han logrado dinamizar su rentabilidad a partir del envío de las remesas, en especial los bancos comerciales, las casas de cambio, las compañías de mensajería (couriers), las entidades trasmisoras de dinero y los encomenderos.

Junto con las remesas, la última década caracteriza en el marco de una lógica regional de acumulación dos ejes ligados al sector construcción: el desarrollo inmobiliario y el turístico. Una forma particular de caracterizar lo anterior se puede extraer de la siguiente frase de Ricardo Poma, presidente del Grupo Roble: "Hemos contribuido a cambiar la fisonomía de las ciudades en la región" (Contreras, 2012). Con esta frase, Poma sintetiza la apuesta de algunas élites empresariales salvadoreñas en la construcción de un nuevo concepto de desarrollo inmobiliario, no solo de condominios o viviendas para clases medias y altas en zonas específicas, como en Escalón, Antiguo Cuscatlán, Santa Elena, Comasagua y Carretera al Puerto de La Libertad, sino también por la apuesta regional de un desarrollo inmobiliario integrado por centros comerciales, hoteles y centros corporativos.

El sector construcción inició con un importante crecimiento a partir del 2003 (Figura 4) con inversiones de 324 millones de dólares y finalizó en el 2008, momento en el cual la ola de la crisis comenzó a azotar la economía salvadoreña. Aun así, el 2010 permitió concluir importantes proyectos privados de vivienda, centros comerciales y centros corporativos (Plaza Centro, Torre Pedregal y Plaza Tempo), así como con los intentos estatales de convertir a El Salvador en un centro logístico y de distribución, como el Puerto de la Unión inaugurado en el 2010 y la Carretera Longitudinal Norte fundado en el 2012. 
Figura 3

TRÁFICO ANUAL DE PASAJEROS POR LÍNEA AÉREA

AEROPUERTO INTERNACIONAL DE EL SALVADOR

(2000-2016)

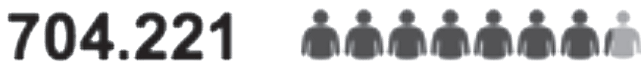 TACA INTERNATIONAL AIRLINES, S. A.}

266.914 inis

UNITED AIRLINES, INC.

229.406 inn

LÍNEAS AÉREAS COSTARRICENSES, S. A. (LACSA)

\subsection{7}

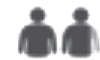

DELTA AIRLINES, INC.

169.226

AMERICAN AIRLINES, INC.

140.664 in

COMPAÑÍA PANAMEÑA DE AVIACIÓN, S. A. (COPA)

52.686

AEROLITORAL, S.A.DE C.V. (AEROMEXICO)

50.599

SPIRIT AIRLINES, INC.

46.740

a.

VUELOS ECONÓMICOS CENTROAMERICANOS, S. A.DE C.V.2, 319

25.004

i

IBERIA LÍNEA AÉREAS DE ESPAN̄A, S. A. OPERADORA

23.973

TRANS AMERICAN AIRLINES, S. A.

5.750

AEROVÍAS DEL CONTINENTE AMERICANO, S. A.

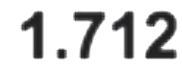

OTROS COMERCIALES

Fuente: Elaboración propia a partir de Comisión Portuaria Autónoma Aeropuerto Internacional El Salvador, 2016. 


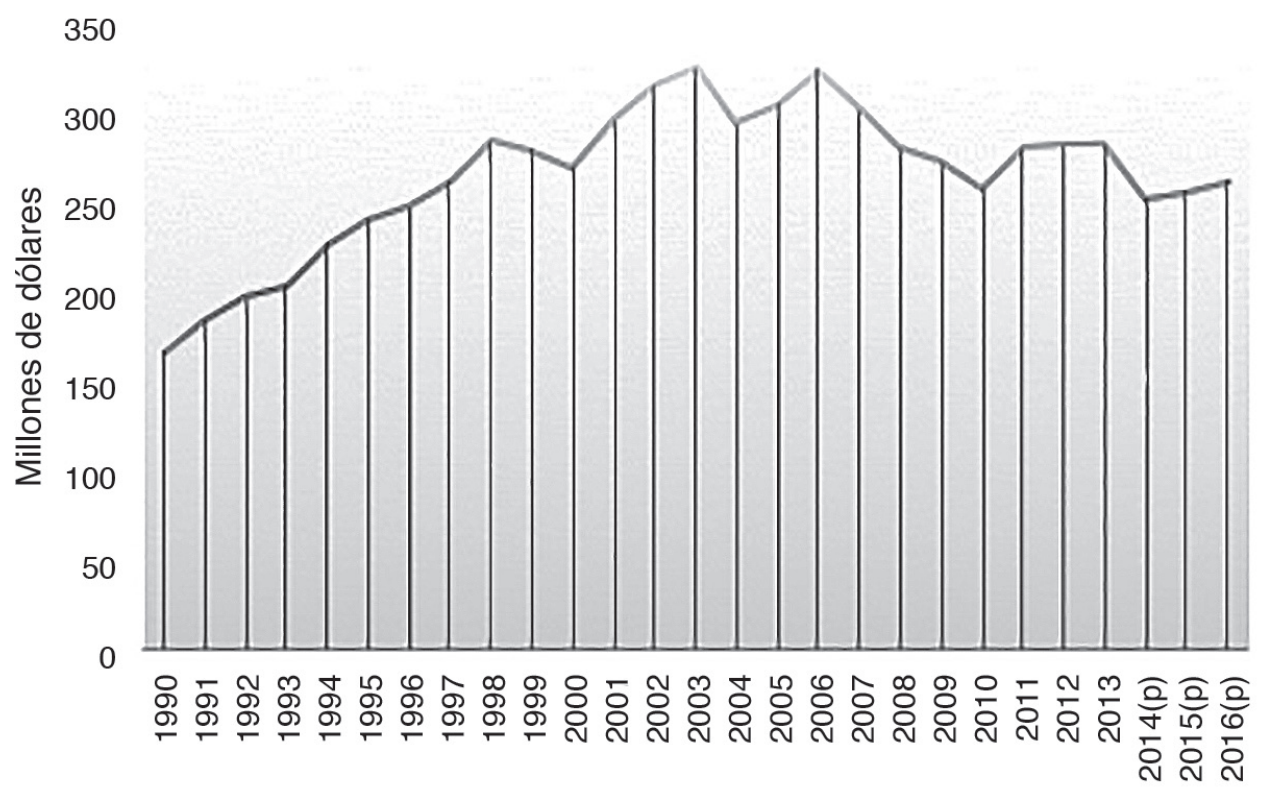

Fuente: Producto Interno Bruto (PIB) por Rama de Actividad Económica. Banco Central de Reserva El Salvador. (p) Datos preliminares.

Desde el sector privado, según la Cámara Salvadoreña de la Industria de la Construcción (CASALCO), si bien se pueden identificar 447 empresas ligadas al sector construcción, también resulta fácilmente rastreable una concentración por grandes proyectos en solo ocho empresas (Tabla 2). De estas ocho empresas, tres (Inversiones SIMCO S.A, grupo Roble y Agrisal) han asumido a la región como su eje de acumulación con una nueva estrategia de desarrollo de centros integrados (hoteles, centros comerciales y centros corporativos). Es claro también que esta expansión ha sido clave en el establecimiento de redes interélites y con élites de otros países de la región, lo cual les ha abierto las puertas a zonas de alta plusvalía y desarrollo económico. 
Tabla 2

PRINCIPALES DESARROLLADORES INMOBILIARIOS EN EL SALVADOR

\begin{tabular}{|c|c|c|}
\hline Grupo & Socios & Principales proyectos \\
\hline \multirow[t]{2}{*}{ Inversiones SIMCO } & Familia Simán & $\begin{array}{l}\text { 1996. Centro Comercial Galerías } \\
\text { 2011. Plaza Centro }\end{array}$ \\
\hline & $\begin{array}{l}\text { Félix José Simán Jacir, } \\
\text { presidente }\end{array}$ & \\
\hline Constructora Bolívar & $\begin{array}{l}\text { Familia de Sola } \\
\text { Diego de Sola } \\
\text { Gerente General }\end{array}$ & 2011. Plaza Centro San Salvador \\
\hline $\begin{array}{l}\text { Desarrolladora TP Grupo } \\
\text { Nuilas }\end{array}$ & - & $\begin{array}{l}\text { 2009. Las vistas en Paseo Escalón y } \\
\text { Condado Santa Elena- }\end{array}$ \\
\hline $\begin{array}{l}\text { Urbánica, Desarrollos } \\
\text { Inmobiliarios }\end{array}$ & $\begin{array}{l}\text { Familia Dueñas } \\
\text { Alejandro Dueñas, } \\
\text { director ejecutivo }\end{array}$ & $\begin{array}{l}\text { 2006. La Castellana y la Colonia } \\
\text { Residencial El Espino } \\
\text { 2007. Hotel Courtyard Marriott y el edi- } \\
\text { ficio de oficinas corporativas de Banco } \\
\text { Promerica }\end{array}$ \\
\hline $\begin{array}{l}\text { Constructora Salazar } \\
\text { Romero, S.A. }\end{array}$ & Raúl Salazar, presidente & $\begin{array}{l}\text { Cuidad Real } \\
\text { Ciudad Versalles }\end{array}$ \\
\hline Grupo Arquero & $\begin{array}{l}\text { Gustavo Figueroa, } \\
\text { presidente }\end{array}$ & 2010. Torre Terra Alta \\
\hline Grupo Roble & $\begin{array}{l}\text { Familia Poma } \\
\text { Ricardo Poma, presidente }\end{array}$ & $\begin{array}{l}\text { 2010. Torre Pedregal } \\
\text { 2011. Courtyard by Marriott Panamá } \\
\text { Metromall }\end{array}$ \\
\hline Grupo Agrisal & $\begin{array}{l}\text { Familias Meza, Palomo y } \\
\text { Quiñónez }\end{array}$ & $\begin{array}{l}\text { 2008. Ampliación de Plaza Mundo } \\
\text { 2009. Plaza Futura } \\
\text { 2011. Holiday Inn } \\
\text { 2012. Plaza Tempo }\end{array}$ \\
\hline
\end{tabular}

Fuente: Elaboración propia a partir de los sitios web oficiales. 
La visión de los centros integrados puede afirmarse ha sido una respuesta a la propia dinámica del crecimiento y visión del capitalismo salvadoreño: priorizar el consumo.

Las apuestas de El Salvador en el caso del Puerto de la Unión y la Carretera Longitudinal Norte (CLN) forman parte también de una lógica de acumulación regional, proyecto Mesoamérica; ${ }^{16}$ es decir, de una visión integrada de país intercomunicado con Guatemala y Honduras; el puerto de la Unión al Este de El Salvador, Puerto Barrios en Guatemala y puerto Cortés en Honduras, lo que facilitaría el trasiego de mercancías entre los tres países y los mercados extraregionales (Acuña et al., 2011).

La CLN tiene como objetivo la conectividad con los megaproyectos mineros e hidroeléctricos de la Zona Norte, pues son funcionales y necesarios para la proyección del área metropolitana de El Salvador como centro de distribución y logística, y eje territorial del patrón de acumulación salvadoreño.

De la mano de la construcción, el Salvador ha impulsado el turismo como eje de acumulación para las élites empresariales salvadoreñas, especialmente por las relaciones que algunas mantienen -franquicias- con cadenas transnacionales (Holliday Inn, Crowne, Marriot, entre otras) y por ser el turismo una apuesta regional centroamericana.

En este sentido, la apuesta es de remplazar aquellos ingresos provenientes del sector agrícola tradicional (Rivers-Moore, 2016, p. 11). En el marco de este patrón, el valor económico "producido" se basa en la extracción de uno asignado a los animales, los paisajes y la gente en forma de precios, por los cuales, los turistas desean pagar para ver, fotografiar y tocar (Ramírez-Cover, 2007).

En el caso centroamericano,

(E)l turismo, como ningún otro sector económico, se ha convertido en una apuesta regional desde que en la Declaración de Montelimar los gobiernos centroamericanos se comprometieran a lograr - la integración turística regional, que permita unir nuestros recursos, voluntades y esfuerzos, a fin de proyectar ante el mundo la imagen y ventajas de ofrecer un destino turístico regional único (Gómez y Ortíz, 2010, p. 1).

Si bien las infraestructuras turísticas y el modelo turístico regional son aún débiles en El Salvador, como se manifiesta en el bajo flujo de turistas a El Salvador (Figura 5), el crecimiento y llegada de turistas casi se ha duplicado en la última década. 
Figura 5

LLEGADA DE TURISTAS A EL SALVADOR

2000-2012

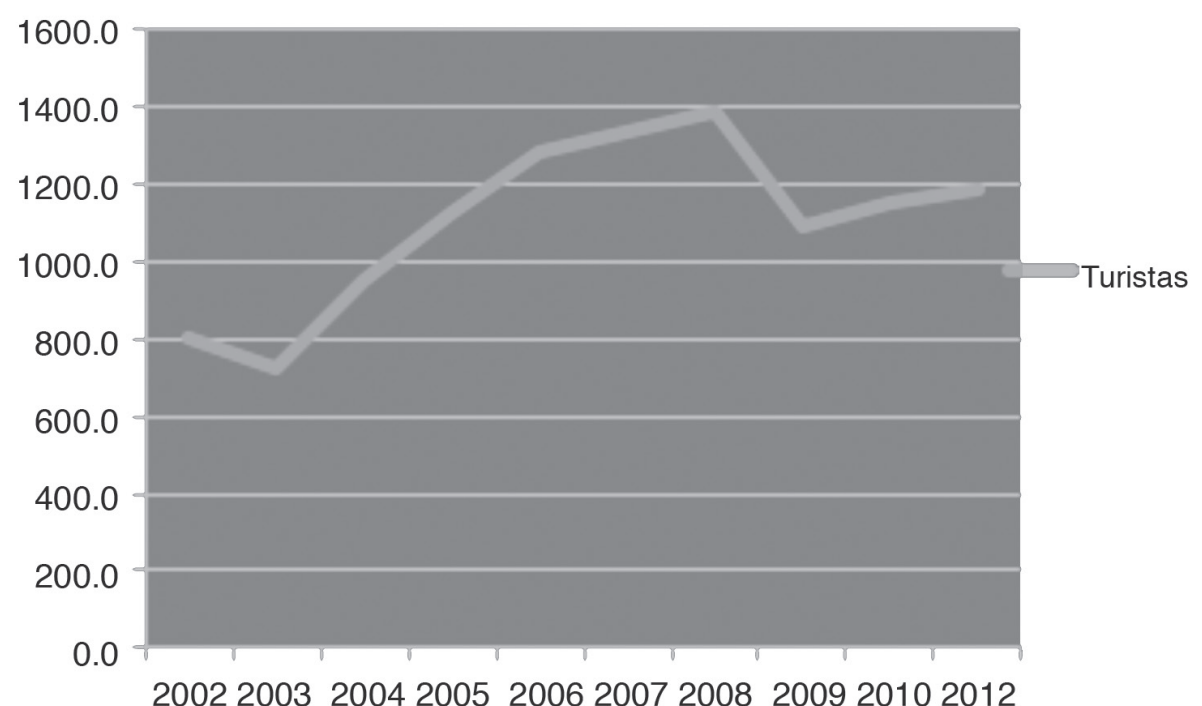

Fuente: Consejo Centroamericano de Turismo. Secretaría General del Sistema de la Integración Centroamericana.

En el caso de El Salvador, con la aprobación la Ley de Turismo del 2005, se sigue el "modelo costarricense" de promover desde el Estado el desarrollo turístico, principalmente de playa y negocios, a través de incentivos y exoneraciones fiscales a los desarrolladores.

En el caso del turismo de playa en el marco del Fondo de Apuesta por Inversiones, incluido dentro del proyecto Fomilenio II, se espera apoyar el desarrollo de la franja costero-marina (Ahuachapán, Sonsonate, La Libertad, La Paz, San Vicente, Usulután, San Miguel y La Unión) por hasta USD100 000 no reembolsables ${ }^{17}$ a inversores privados que decidan instalarse en el área (Flores, 2013).

En el caso de los complejos integrados, estos se ubican principalmente en centros de alta plusvalía y desarrollo de San Salvador. Al decir del Ministerio de Turismo Salvadoreño: "San Salvador, su capital, posee la ubicación estratégica y la accesibilidad aérea idóneas para la celebración de reuniones, convenciones, congresos y otros tipos de eventos" (MITUR, 2013).

En suma, los ejes de acumulación de El Salvador hoy, compiten entre aquellos más rentables en manos de grupos regionales o transnacionales, y aquellos otros espacios que han sido poco a poco acaparados por las élites empresariales 
en solitario, en asocio con otras élites o con transnacionales. Puede decirse, entonces, que en torno al patrón de acumulación salvadoreño se consolida el eje de acumulación abierto por las remesas y los flujos migratorios externos, así como el desarrollo inmobiliario en el área metropolitana de San Salvador y en zonas de alta plusvalía de otros países de la región; la apuesta por el turismo en la costa pacífica, la CLN y los nuevos proyectos hidroeléctricos (El Chaparral, Sensunapán, El Cimarrón). Sin embargo, la crisis en los EE. UU. da cuenta de la fragilidad y volatilidad del propio patrón, probablemente por esto algunos otros países de la región (Costa Rica y Nicaragua) han iniciado a lanzar sus apuestas a la creciente República Popular de China.

\section{Los gobiernos del FMLN y las empresas del ALBA}

La llegada del FMLN al poder en El Salvador modificó no solo la interacción con el Estado, sino que también facilitó el poder consolidar un nuevo núcleo de empresas y empresarios en algunos sectores. En el marco de las relaciones con el nuevo gobierno de izquierda, lejos de una ruptura radical con las élites económicas, el equipo del presidente Funes instaló, en el 2011, el Consejo Nacional para el Crecimiento (CNC); entidad integrada por el secretario técnico de la Presidencia, el ministro de Hacienda, el ministro de Economía, el ministro de Agricultura y Ganadería y el presidente del Banco Central de Reserva, así como por 6 de los más importantes miembros de la élite salvadoreña: Roberto Murray Meza, Francisco de Sola, Francisco Callejas, José Roberto Dutriz, Juan Carlos Eserski y Ricardo Poma. Nacido dentro del dentro del Plan de Acción del Asocio para el Crecimiento, acuerdo firmado con los EE. UU., el CNC tenía como objetivos "promover un ambiente de confianza y mejorar el clima de negocios e inversiones en actividades o sectores considerados como estratégicos" (BCR, 2013).

No sin contratiempos, el CNC ha funcionado estratégicamente manteniendo abiertos los mecanismos y espacios de diálogo con los grandes empresarios, por un lado, y favoreciendo, por otro, la atracción y el desarrollo de inversiones, junto con los EE. UU.

Además, y más importante aún para entender las relaciones con las élites económicas ha sido el impulso dado a las empresas del asocio salvadoreño venezolano: ALBA petróleos. Nacida como una empresa de economía mixta en el año 2006 en el marco del acuerdo de PetroCaribe con Venezuela, Alba petróleos conforma la Asociación intermunicipal Energía para El Salvador (ENEPASA). En alguna medida, Alba petróleos se ha constituido en lo que en su momento fue el sector financiero para las élites salvadoreñas a mediados de los años noventa, al proveer de dinero fresco a un nuevo núcleo empresarial que ha buscado acceder a mercados hasta ahora acaparados por pocos grupos empresariales: medios de comunicación, transporte aéreo, finanzas, 
energía e hidrocarburos. La mayoría de estas empresas se ha abierto a través de préstamos y subsidios destinados a un pequeño núcleo de personas, políticos del FMLN en su mayoría (Tabla 3).

Tabla 3

EMPRESAS DEL ALBA

\begin{tabular}{|c|c|c|}
\hline Empresa & Sector & Descripción \\
\hline Alba Petróleos & Hidrocarburos & $\begin{array}{l}\text { Comercialización de productos } \\
\text { derivados del petróleo }\end{array}$ \\
\hline $\begin{array}{l}\text { Vuelos Económicos Centroamericanos } \\
\text { (VECA AIRLINES) }\end{array}$ & Transporte aéreo & $\begin{array}{l}\text { Vuelos baratos entre los países } \\
\text { de América Central }\end{array}$ \\
\hline Arrocera de El Alba & Agrícola & Venta y distribución de granos \\
\hline Tu Solidaria & Financiero & $\begin{array}{l}\text { Créditos a pequeños y medianos } \\
\text { empresarios }\end{array}$ \\
\hline GenteVE & Medios de comunicación & Canal de televisión abierta \\
\hline AlbaTech Green Energy & Energía & $\begin{array}{l}\text { Producción y comercialización } \\
\text { de paneles solares }\end{array}$ \\
\hline
\end{tabular}

Fuente: Elaboración propia a partir de las páginas web de las compañías.

Si bien estas empresas tuvieron como objetivo ampliar los competidores en mercados altamente concentrados (transporte aéreo y medios de comunicación, por ejemplo) y a su vez disputarle a las élites económica sus fuentes de acumulación, a inicios del año 2017 tres de estas empresas (VECA, Tu Solidaria y Arrocera el Alba) debieron suspender sus operaciones, negociar su venta o pactar con otras compañías. Ahora bien, estas empresas y sus dirigentes no podrían considerarse aún como élites emergentes o parte de un nuevo eje del patrón de acumulación; pues, a diferencia de los ejes de remesas y turismo cuyo trazado depende más de una visión y estrategia regional de acumulación, en el caso del ALBA esta es una estrategia dependiente, por un lado, del financiamiento internacional de Venezuela y, por otro lado, de las victorias electorales del FMLN en los municipios en donde está presente.

\section{Conclusiones}

Centroamérica sigue siendo un laboratorio económico. En el caso de El Salvador mucho ha cambiado desde los últimos estudios sobre élites (Segovia, 2002 y 2005). Las dinámicas propias del capitalismo volátil de El Salvador, su dependencia de las remesas, su economía sustentada en los servicios y su alta penetración por parte 
del capital regional y transnacional son referentes clave para entender los cambios y continuidades en las élites y el patrón de acumulación salvadoreño.

También es clara la salida de las élites salvadoreñas de los ejes de acumulación más rentables (sector financiero, por ejemplo) y su apropiación por parte de capitales regionales, principalmente de México y Colombia, así como de capitales transnacionales. La competencia y la compra-venta de empresas tradicionalmente de las élites han facilitado la apropiación oligopólica de ciertos mercados (banca, telecomunicaciones, seguros, entre otros) por parte de capitales regionales y transnacionales, y sobre todo ha favorecido el acceso a recursos frescos a las élites empresariales locales que vendieron sus empresas. En este sentido, El Salvador hoy vive inmerso en una economía más transnacionalizada y con élites económicas con mayor liquidez para sus inversiones.

En términos generales, también se puede ver una nueva forma de concebir territorialmente a El Salvador a partir de los ejes de acumulación de turismo y desarrollo inmobiliario. Por un lado, un centro desarrollado y apto para los negocios (San Salvador) y, por otro, una costa rica en recursos y playas, con amplios incentivos para la inversión turística, y regiones de interconexión con mercados regionales y extraregionales.

Todo lo anterior define un horizonte y una clara diferenciación entre las élites tradicionales, renovadas en los años 90 y las élites del siglo XXI. En general, las primeras eran altamente cohesionadas empresarial y políticamente frente a una posible victoria de la izquierda del FMLN y enlazadas en torno al sector bancario (A. Schneider, 2012). Sin embargo, las élites salvadoreñas de hoy (2017) están mayormente vinculadas a los sectores de servicios y al comercio, sin bases en el sector financiero y con un mercado más amplio que el nacional.

Además, la cohesión que históricamente las caracterizó fue rota desde el primer gobierno del FMLN en el año 2009, momento en el cual el gobierno de Mauricio Funes logró negociar cuotas, negocios, publicidad y recursos con ciertas élites. En este sentido, el vínculo político-empresarial, si bien no se rompió del todo como constata la instauración del $\mathrm{CNC}$, sí ha hecho aguas con la emergencia de otra fuerza política de centro derecha (GANA), más cercana al FMLN que a ARENA.

La pérdida de control sobre los ámbitos ejecutivo y legislativo por parte de estas élites tradicionales ha posibilitado, que entre otros aspectos, El Salvador haya avanzado en tres reformas fiscales $(2009,2011$ y 2014) con clara orientación de tasar por primera vez en los últimos treinta años a los más ricos. Asimismo, estas disputas interélites se han sumado a otro ámbito cuyo control estuvo históricamente en manos de las élites tradicionales, o lo que los salvadoreños denominan la aristocracia: los medios de comunicación.

Si bien los medios tradicionales en prensa escrita y televisión se mantienen en las manos de las mismas familias (Eserski, Altamirano, Dutriz y Borja), nuevos medios en televisión, radio y web han surgido de la mano de esas nuevas élites, denominadas 
por los salvadoreños como "árabes" (Saca, Bukele y Salume) y de las élites del ALBA (La Página, Orbita). Lo anterior, sin lugar a dudas, ha implicado una reducción en la capacidad de influencia de las élites tradicionales sobre la sociedad salvadoreña (Robles-Rivera, 2017).

Por último, si se considera que las élites económicas salvadoreñas dependen económicamente de la "exportación de gentes" y la importación de remesas, valdría preguntarse entonces, hasta qué punto estarían las élites salvadoreñas dispuestas a modificar las condiciones que promueven la expulsión de la población salvadoreña, teniendo en cuenta que esta es su mayor fuente de riqueza. Asimismo, teniendo en cuenta que las élites salvadoreñas tradicionales ven disputada su hegemonía por otras élites (árabes y ALBA), hasta qué punto la propia fragmentación imposibilita los acuerdos nacionales que prioricen lo colectivo/nacional y no lo particular/individual.

\section{Notas}

En general para América Central es claro, sobre todo en el último quinquenio el surgimiento de un nuevo eje de acumulación basado en el narcotráfico, la violencia y el lavado de dinero. La apertura de este eje ha sido favorecida por una endémica debilidad institucional y altas tasas de corrupción en la región, el re ubicación de carteles de la droga en la región, producto de la militarización de la lucha contra las drogas en México y Colombia (Iniciativa Mérida y Plan Colombia) y flujos de dinero sin límite de suma que necesitan insertarse de manera legal en el sistema financiero. Producto de lo anterior, en la región han surgido grupos vinculados sobre todo al lavado de dinero que se han graduado de clases bajas y medias a clases altas, con vínculos políticos y económico a nivel nacional y regional. La expansión económica de estos grupos varia, pero sus inversiones suelen priorizar el desarrollo inmobiliario y bienes raíces, aunque también sus actividades suelen desarrollarse en la exportación, encomienda, centros de diversión (clubes nocturnos), compra y venta de vehículos de lujo, entre otros. Sin embargo, el estudio de estos grupos trasciende el objeto de investigación del presente trabajo, aunque como se afirmó anteriormente son parte constitutiva de una nueva élite y de un nuevo eje de acumulación.

Familia descendiente de José Jorge Simán, originario de Jerusalén. Procedente de Palestina llegó en 1890 junto con su esposa Natalia Jacir.

Familia descendiente de Jorge Antonio Zablah. Palestino emigrado a El Salvador en 1898.

La conformación de élites en América Central a partir de una migración de grupos étnicos específicos es particularmente relevante pero con muy poco estudio sobre cada caso, por ejemplo, los libaneses y judíos en Costa Rica o árabes y libaneses en Honduras.

5 Un ejemplo de estas alianzas producto de la salida de estos grandes capitales a los EE. UU. tiene que ver con la fundación en los años ochenta de la empresa Bain Capital, fundada en los EE.UU. por el ex candidato presidencial Mitt Romney con la ayuda de capitales de las familias Poma, Salavierra, de Sola (Dada, 2012)

Familias Cristiani, Baldochi, Dueñas, De Sola, Hill y Salaverría.

Familias Meza Ayau, Meza Hill, Sol Meza., Quinónez Meza y Álvarez Meza. 
Familia Poma.

“Con la incorporación unilateral al ámbito monetario de los EE. UU. se reducen las posibilidades para negociar una futura integración monetaria simétrica (si es que ésta fuera una opción a seguir). El país que se dolariza unilateralmente archiva, sin obtener nada a cambio, parte importante de su soberanía económica, como lo es la política monetaria y cambiaria. Esta decisión hará mucho más vulnerables y dependientes de la Reserva Federal de los EE. UU. (FED) a las economías que opten por esta vía, sin que tengan opción alguna para influir en sus decisiones" (Acosta, 2001).

10 Ligado a las familias Belismelis, Catani, Papini, Álvarez Freund, Cohen, Sol, Escalante Sol, Quiñónez Sol, Palomo, entre otras.

11 Perteneciente a las familias Simán Jacir, Simán Siri, Salume, Zablah Touché.

12 Ligado a las familias Baldochi Dueñas, Kriete Ávila, Dueñas, Palomo Déneke, Araujo Eserski, Shildknecht, Pacas Díaz, y Cohen.

De las familias Meza Ayau, Meza Hill, Sol Meza, Quiñónez Meza y Álvarez Meza.

Ligado a las familias Cristiani, Salaverría, Hill, Kriete, entre otras.

Familia Kriete.

Es esta "otra" nueva Mesoamérica lejos de los discursos de "cooperación, desarrollo e integración", la que articula un espacio de proyección geoestratégico y geoeconómico, a través de la cual se proyecta la reconstitución hegemónica de los EE. UU. en la región tras el fracaso del ALCA, y por medio de la cual se crean las condiciones físicas, jurídicas y simbólicas para que el capital transnacional metropolitano, y los grupos de poder regional puedan expandirse.

Este tipo de incentivos ha sido utilizado en complejos y desarrollos turísticos en Costa Rica por ejemplo, y ha favorecido que las élites tradicionales acaparen los incentivos por su peso y capacidad económica.

\section{Bibliografía}

Acosta, Alberto. "El falso dilema de la dolarización". Nueva Sociedad, núm. 172, 2001.

Acuña, Guillermo et al. "Trabajadores migrantes y megaproyectos en América Central”. San Salvador: PNUD/UCA (2011).

Albiac, María Dolores. Los ricos más ricos de El Salvador. Fundación Heinrich Böll, 1998.

Arias-Peñate, Salvador. Derrumbe del neoliberalismo: Lineamientos de un modelo alternativo. Editorial Universitaria, Universidad de El Salvador, 2008.

Bull, Benedicte. "Diversified Business Groups and the Transnationalisation of the Salvadorean Economy". Journal of Latin American Studies 45.2 (2013): 265-295.

Bull, Benedicte. “Towards a Political Economy of Weak Institutions and Strong Elites in Central America". European Review of Latin American and Caribbean Studies (2014): 117-128.

Bull, Benedicte, Fulvio Castellacci y Yuri Kasahara. Business groups and transnational capitalism in Central America: Economic and political strategies. Palgrave Macmillan, 2014. 
Cárdenas, Julián y Francisco Robles-Rivera. Business Elite Networks for Corporate State Capture in Central American Countries. Rochester, NY: Social Science Research Network, 2017.

Contreras, Carlos. "Ricardo Poma: 'Hemos contribuido a cambiar la fisonomía de las ciudades en la región'”. Revista Summa, 2012.

Durand, Francisco. Riqueza económica y pobreza política: reflexiones sobre las élites del poder en un país inestable. Pontificia Universidad Católica del Perú, Fondo Editorial, 2003.

Flores, Ricardo. "Los inversionistas muestran su cartera a la costa". Diario Digital Contra Punto 4 de noviembre, 2013.

Gómez, Ileana, y Xenia Ortíz. La apuesta por un turismo sostenible en El Salvador: Propuestas para un cambio de políticas. San Salvador: Fundación Prisma, 2010.

Guzmán López, Karla Melissa, y Julian Ernesto Salinas Ventura. “El patrón de acumulación de capital en El Salvador, a partir de la implementación de los PAE y PEE durante el período 1989-2007". Bachelor. Universidad de El Salvador, 2008.

Kasahara, Yuri. "Should I stay or should I go? A comparative study of banking sector policies and the strategies of Central American business groups". Business and Politics 14.4 (2012): 1-43.

Madrid, Cori. "El Salvador and the Central American Free Trade Agreement: Consolidation of a Transnational Capitalist Class". Perspectives on Global Development and Technology 8.2-3 (2009): 189-210.

Paniagua-Serrano, Carlos Rodolfo. El bloque empresarial hegemónico salvadoreño. Universidad centroamericana” José Simeón Cañas, 2002.

Ramírez-Cover, Alonso. “Conflictos socioambientales y recursos hídricos en Guanacaste: Una descripción desde el cambio en el estilo de desarrollo (1997-2006)". Anuario de Estudios Centroamericanos 33/34 (2007): 359-385.

Rettberg, Angelika. "The Private Sector and Peace in El Salvador, Guatemala, and Colombia”. Journal of Latin American Studies 39.3 (2007): 463-494.

Revista Summa. "Lista de fusiones y adquisiciones anunciadas públicamente en América Central y el Caribe entre Marzo y Septiembre 2012", 2012.

Rivers-Moore, Megan. Gringo Gulch: Sex, Tourism, and Social Mobility in Costa Rica. University of Chicago Press, 2016.

Robinson, William I. Transnational conflicts: Central America, social change and globalization. Verso, 2003.

Robles Rivera, Francisco. “Transformaciones y concentración en grupos de poder económico en Costa Rica (1980-2012)". Revista mexicana de sociología 76.1 (2014): 37-58.

Robles-Rivera, Francisco. "Los de entonces ya no son los mismos. Acumulación por desposesión en la última década en El Salvador y Costa Rica". Anuario de Estudios Centroamericanos 37.1-2 (2011): 105-137.

Robles-Rivera, Francisco. "Media Captured: Elites and Networks in El Salvador and Costa Rica". Doctoral dissertation. Freie Universität Berlin, 2017.

Robles-Rivera, Francisco. "Nuevos espacios de acumulación: Modelo de ajuste estructural en El Salvador y Costa Rica (1980-1999)". Revista de Ciencias Sociales, 128-129, (2010).

Rocha, José Luis. "12 mil millones en remesas: ¿Quién se come ese mandado?" Revista Envio, 2013.

Salas-Porras, Alejandra. “Globalización y proceso corporativo de los grandes grupos económicos en México". Revista Mexicana de Sociología (1992): 133-162. 
Schneider, Aaron. State-Building and Tax Regimes in Central America. Cambridge University Press, 2012.

Schneider, Ben Ross. "A Comparative Political Economy of Diversified Business Groups, or How States Organize Big Business". Review of International Political Economy 16.2 (2009): 178-201.

Scott, John. "Modes of Power and the Re-Conceptualization of Elites". The Sociological Review 56 (2008): 25-43.

Segovia, Alexander. "Centroamérica después del café: el fin del modelo agroexportador y el surgimiento de un nuevo modelo económico". Revista Centroamericana de Estudios Sociales (2004).

Segovia, Alexander. “Integración real y grupos de poder económico en Centroamérica: implicaciones para el desarrollo y la democracia de la región". San José: Fundación Friedrich Ebert (2005).

Segovia, Alexander. Transformación estructural y reforma económica en El Salvador: el funcionamiento económico de los noventa y sus efectos sobre el crecimiento, la pobreza y la distribución del ingreso. F y G Editores, 2002.

Francisco Robles Rivera. Costarricense. Actualmente realiza su doctorado en Ciencias Políticas en la Freie Universität Berlin. Ha sido profesor de la Escuela de Ciencias de la Comunicación Colectiva e investigador del Instituto de Investigaciones Sociales de la Universidad de Costa Rica y profesor del Instituto de Estudios Latinoamericanos de la Universidad Nacional de Costa Rica. Es autor de diferentes textos sobre grupos de poder económico en Costa Rica y El Salvador: Los de entonces, ya no son los mismos. Acumulación por desposesión en El Salvador y Costa Rica en la última década. También, Transformaciones y concentración en los Grupos de Poder Económico en Costa Rica (1980-2012).

Contacto: francisco.robles@fu-berlin.de

ORCID: 0000-0002-0117-3515 